This is the 'author's original' (AO) version of a forthcoming article due to appear in Notes and Queries, June 2019. The 'version of Record' (VoR), which incorporates minor changes, will be available shortly through the journal's website.

\title{
LATER ADDITIONS TO THE ANGLO-NORMAN TEXTS OF BRITISH LIBRARY, ADD. MS. 598391
}

Acquired by the British Library in 1976, Additional MS 59839 is a theological miscellany dating from the late thirteenth or early fourteenth century. ${ }^{2}$ Its 44 sections contain over 35 Latin texts that range from copy of St. Bonaventure's Breviloquium (fols. 6-51v; section 6) to Biblical commentaries (fols. $167 r-177 v, 178 v-183 r$; section 38). Sections 40 and 41 of the codex, however, transmit three texts in Anglo-Norman French: a method for curing a three-day fever (Dean $\S 440$, fol. 190v), the prose Prophecies de Merlin (Dean $\S 18$, fols. 191v-193v), and a version of Urbain le courtois (Dean $\S 231$,

\footnotetext{
${ }^{1}$ I would like to thank Dr. Elizabeth Williamson and Dr. Charlotte Tupman for their advice and guidance pertaining to the the Tudor-period addition to the MS, and Heather Hind and SarahJayne Ainsworth for their input relating to the later addition. Any errors are of course my own.

${ }^{2}$ A dating of this manuscript to c. 1300 has been put forward by both the 1976 auction catalogue and by Goering and Mantello's study of other material within the codex. See '863. Prophecies of Merlin; Quaestiones of Grossteste's circle and other texts', in Bibliotheca Phillippica: Catalogue of Manuscripts on Papyrus, Vellum and Paper (London, 1976), 23-7, and J. Goering \& F. A. C. Mantello, 'Two opuscula of Robert Grosseteste: De vniversi complecione and Exposicio canonis misse', Mediaeval Studies, liii (1991), 89-123. The British Library's own catalogue ascribes a broader date range of 'late 13th or early 14th cent.', and notes its later ownership by the 'vicarius de Gauylton', while Dean offers a slightly later dating of the early 14th century only. See '59839. Theological Miscellany', in The British Library Catalogue of Additions to the Manuscripts, New Series 1976-1980 (London, 1995), 30-33, and R. Dean, Anglo-Norman Literature: A Guide to Texts and Manuscripts (London, 1999), 17, 131, 237. As the auction catalogue notes (23), the attribution of one of the Prophecies de Merlin to Edward II 'giv[es] a terminus post quem for this part of the manuscript of 1307.
} 
fols. 194r-195r). Both published descriptions of the manuscript have provided details on these vernacular pieces; neither, however, has acknowledged the presence, alongside the manuscript's latter two Anglo-Norman texts, of a third language. Both Urbain and the Prophecies have, in Add. MS 59839, received additions in English centuries after they were originally compiled into the codex. ${ }^{3}$ Taken together, these two additions, one in a sixteenth-century hand, and the other added two to three centuries later, constitute a valuable case study in attitudes towards the medieval manuscript book in the centuries beyond its initial commission, construction and consumption.

\section{English glosses to the Prophecies of Merlin}

It is to the longer of these two texts that the most recent reader's notes have been added. The base text, beginning on fol. 191v under the rubric 'Les p(ro)phecies Merlyn du Roys D’Engleterre', represents the “'Original” Prose Version' of the Prophecies tradition as outlined in in Smallwood's classification, ${ }^{4}$ and is also found in at least 11 other codices. In this particular manuscript, the Prophecies are executed in the same hand as the later Urbain text across a single column, with systematic red-washing of capitals following the punctus as well as of certain proper nouns (Paris, Engleterre). Nouns, albeit common ones, are also the subject of the later additions, which appear to have been executed in an eighteenth-century Italic hand and which gloss eight nouns or noun phrases across the five folia into English. The glosses are executed in the margins of the text, with the relevant French terms in the base text marked with

\footnotetext{
${ }^{3}$ The sixteenth-century addition is briefly acknowledged in the auction catalogue as a possible indicator of provenance (23).

4 T.M. Smallwood, 'The Prophecy of the Six Kings', Speculum, Ix (1985), 571-92 (here 573-7). As Dean notes, Smallwood does not make reference to this manuscript in his conspectus.
} 
a range of sigla including a cross, asterisks, and, on the fourth and fifth occasions, the letters (a) and (b). The glosses are as follows: ${ }^{5}$

\begin{abstract}
[f. 191v] vn aignel: a Lamb. / leuers: Lips / lange: Tongue / vn low: Loup a wolfe. Louve a shee wolfe. / dun rouge goupil: a Red Fox. / ses orailles: Ears. [f. 192r] vn cheuere: a shee-Goat. / [f. 193v] foille de sapine: a Fir tree.
\end{abstract}

The pattern of glossing, while sporadic, is not entirely random. Since the Prophecies have as their basis a series of zoomorphic descriptions that portray successive monarchs as (among other amimals) lambs, wolves, and lions, the glosses' concentration on the names of animals (aignel, low, goupil, chevere) points to a later individual simply adding notes where necessary to facilitate their understanding of the text. The unsystematic nature of the glossing, however, renders this explanation alone unsatisfactory. While the absence of a gloss to dragoun (f. 191v) can be explained through the similarity of the Anglo-Norman term to English, the same cannot be said for either sengler (fol. 192v) or ane (fol. 193r), both of which are also left unglossed in spite of their lack of cognates in English. A more subtle function of the glosses is hinted at by the fourth gloss on fol. 191v, which makes use of modern French alongside English: here, the modern French terms 'loup' and 'louve' are incorporated into the gloss of the original Anglo-Norman low, along with their respective English translations. Almost all of the nouns glossed in this text would have changed in orthography between 1300 and the $18^{\text {th }}$ century, and the modernising treatment of the noun low, as the clearest example of a distinctive Anglo-Norman orthography,

\footnotetext{
${ }^{5}$ Glosses have been transcribed following the conventions employed in T. Hunt, Teaching and Learning Latin in 13th-Century England. Volume 1: Texts (Cambridge, 1991). Only the letterbased sigla have been retained in this transcription.
} 
suggests a second function of the glossing; namely, that the individual responsible sought not only to understand a medieval text, but also to illustrate the evolution of language in the process.

\section{'Remenbre to wryt to master Joan': 'marks of recording' alongside Urbain le courtois}

The second set of additions to the original French texts can be found several folios later, immediately following the conclusion of the courtesy text known as Urbain le courtois; unlike the glosses discussed above, however, this addition constitutes a discrete textual unit in its own right. ${ }^{6}$ The 158 lines that constitute this version of Urbain conclude early on fol. 195rb; a red-washed 'Am[en]', written in the same hand as the main body of the text, suggests that the text was envisioned as completed at this point, rather than being abandoned. In the lower two-thirds of the column, however, a much later individual (c. 1520-1570) has added a note in a rather untidy Secretary hand. At the outset, the anonymous individual who made the addition obeyed the fourteenth-century ruling pattern; this discipline is not retained, however, beyond the fourth line, with the result that the twelve-line addition ultimately extends over a space equivalent to approximately 15 lines of the original ruling. Unlike the glosses to the Prophecies, this addition, of which I here provide a tentative transcription, is entirely unconnected to the text next to which it appears; it has, in Sherman's formulation, 'more to do with the life of the reader than the life of the text..7

\footnotetext{
${ }^{6}$ H.R. Parsons, 'Anglo-Norman Books of Courtesy and Nurture', PMLA, xliv (1929), 383-455. Parsons' corpus of eight manuscripts does not include this manuscript, and similarly omits both MS Harley 2253 (where Urbain is present on fols. 112r-113v) and Cambridge, Emmanuel College Library, MS 106 (fols. 46r-48v). It is with the Emmanuel College manuscript that the Urbain version found in Additional MS 59839 has a particularly close correspondence.

7 W.H. Sherman, 'What Did Renaissance Readers Write in Their Books?', in Books and Readers
} 
Coquet a I[ette]r for me that it

would please hym to delyuer

you a boxe contenynge

5

In p[ri]mis myn Instrument

for my notary offyce

$\mathrm{It}[\mathrm{e}] \mathrm{m}$ he hath my notary synge

Valoris - ij s iiij d

It[e]m he hath on payr beade

10

almer gaudeat with sylver /

[and] a crose of sylver in the

total valour -------- iij s

The scribe responsible for the gloss has chosen to use the space available on fol. 195rb to note down a reminder to write to John (here 'Joan') Coquet, asking him to send a box containing a notarial 'instrument' (referring in this sense to a physical record of the judgements made by a notary). ${ }^{8}$ This would appear to imply that the scribe was involved in some form of service to the owner of the 'Instrument', perhaps acting as a secretary. Coquet is also, as the scribe records, in possession of several other items, including a 'notary synge'

in Early Modern England: Material Studies, ed. by J. Andersen \& E. Sauer (Philadelphia, 2011), 119-37 (here 130). Sherman's comment, while made in reference specifically to handwritten later additions to printed material, is equally applicable in a manuscript context.

${ }^{8}$ An alternative reading of this individual's name as 'Joan Cognet' is viable; indeed, this is the form used in the 1976 catalogue (p. 23). The form of the lower-case $g$ found elsewhere in this hand, however, is characterised by a complete loop below the line; the open nature of this character, albeit with a slight upward 'tick', suggests that the character is in fact a q. Character confusion is present elsewhere in the catalogue, with the rubric to Urbain ('Ici poetz oir coment luy sage soun fuiz aprent') mistranscribed as 'In partz' and 'aprerit' (26). 
(perhaps a signet-ring or seal) and a cross of silver. Lines 9-10 present a greater challenge of comprehension: it is likely that the adjectival clause 'with sylver' refers to the 'on[e] payr beade[s]', which may be the prayer beads alluded to by the Latinate term 'gaudeat'. ${ }^{9}$ A similar difficulty is to be found in the abundance of personal and possessive pronouns in this short note: while 'hym' and 'he' are unambiguous references to Joan Coquet, the presence of both of 'me' and 'you' raises the possibility that the scribe of this note is recording a request dictated to him by an unnamed third individual, whom the scribe may have been serving in a secretarial capacity. A simpler explanation would be that the scribe, whether through error or as a rhetorical flourish, refers to himself both as 'me' and 'you', thus eliminating the need for a third individual.

This single note after Urbain, and the more sporadic glosses to the Prophecies, are unlikely to provide sufficient evidence to allow for the identification of any of the individuals mentioned within them, or to further our understanding of the manuscript's provenance beyond what is already known. The value of these 'marks of recording', however, extends beyond positivistic ideas of 'register[ing] details of the domestic conditions of readers and owners' or 'allow[ing] us a glimpse of the other activities in which the reader was engaged. ${ }^{10}$ Both the eighteenth-century gloss to the Prophecies and the earlier

\footnotetext{
9 The Dictionary of Medieval Latin from British Sources records two instances of gaudeatus designating a set of 'gauds' in relation to the rosary. The term almer is not attested in the DMLBS, although it may be a variant spelling of almus, -a, 'blessed', hence giving 'one pair of beads of the blessed rosary'.

$10 \mathrm{H}$. Brayman Hackel identifies these 'marks of recording', and their usefulness, as part of a paradigm for classifying 'handwritten marks in books' that also includes 'marks of active reading' and 'marks of ownership'. H. Brayman Hackel, Reading Material in Early Modern England: Print, Gender, and Literacy (Cambridge, 2005), 138-9.
} 
note made alongside Urbain demonstrate that modern prohibitions against 'defacing' texts from previous centuries by no means reflect the culture dominant in centuries past. ${ }^{11}$ An Anglo-Norman pseudo-historical text offers new insights into its later users through its acquisition of sporadic glosses, while a quirk of scribal practice that left half of a ruled column blank has provided a later individual with sufficient space to record a mundane personal transaction. MS Add. 59839 suggests that later readers' proclivity for annotating their volumes was not restricted to printed texts, and that the manuscript book continued to function not merely as an object for reverence and preservation, but also as a site for interaction and engagement with the book as an object. ${ }^{12}$

EDWARD MILLS

University of Exeter

11 W.H. Sherman, Used Books: Marking Readers in Renaissance England (Philadelphia, 2008), 151-78.

12 On the relationship between manuscript and printed material in this period, see Brayman Hackel, Reading Material in Early Modern England, 25-34. 